\title{
Immunocytochemical distribution of the protein kinase C substrate B-50 (GAP43) in developing rat pyramidal tract
}

\author{
Th.G.M.F. Gorgels ${ }^{1}$, A.B. Oestreicher ${ }^{2}$, E.J.M. de Kort ${ }^{1}$ and W.H. Gispen ${ }^{2}$ \\ 'Department of Anatomy and Embryology, University of Nijmegen, Nijmegen (The Netherlands), ${ }^{2}$ Division \\ of Molecular Neurobiology, Rudolf Magnus Institute for Pharmacology and Institute of Molecular Biology \\ and Medical Biotechnology, University of Utrecht, Utrecht (The Netherlands)
}

(Received 15 June 1987; Accepted 31 August 1987)

Key words: Development; Pyramidal tract axon; Phosphoprotein B-50; GAP43; Immunocytochemistry;
Nerve growth cone; Rat

The neuron-specific phosphoprotein B-50 is a major substrate of kinase $\mathrm{C}$ in fetal nerve growth cones, neonatal neural and synaptosomal plasma membranes. B-50 is identical to a growth-associated protein GAP43. Similarly, increases in B-50 occur during rat brain development, neuronal differentiation and axon regeneration. To document the relation between the expression of B-50 and the outgrowth of central axons, we studied $\mathrm{B}-50$ in the developing pyramidal tract in rats at postnatal days 2,7 and $90(\mathrm{P} 2, \mathrm{P} 7$ and $\mathrm{P} 90$ ), at the third cervical spinal segment $\mathrm{C}_{3}$, using affinity-purified antibodies to B-50. At P2 and P7, when outgrowth of pyramidal tract fibers is occurring, B-50 immunoreactivity (BIR) is intense in these fibers. BIR is reduced from $\mathrm{P} 2$ to $\mathrm{P} 7$ in the ascending fiber tracts of the cuneatus and the gracilis, which develop earlier. At $\mathrm{P} 90$ when most of the dorsal funiculus fibers have reached their targets and many are myelinated, BIR is dramatically reduced. In agreement, a 10-fold decrease in B-50 content was measured at $\mathrm{P90}$, as compared to $\mathrm{P} 7$. Therefore, our results indicate that $\mathrm{B}-50$ is only expressed relatively abundant in axons of the funiculus posterior during outgrowth. By inference, B-50 may be a differentiating marker to detect elongating fibers.

The ontogenesis of the spinal pyramidal tract in the rat occurs during the postnatal development. Shortly after birth, the leading corticospinal fibers are entering the upper cervical segments of the spinal cord [21], where they occupy the most ventral part of the dorsal funiculus. The spatial and temporal outgrowth of these corticospinal fibers in the spinal white and gray matter in the neonatal rat have been described by Gribnau et al. [8]. They demonstrated that the corticospinal fibers have reached the upper thoracic segments of the spinal cord at postnatal day 2 (P2) and the sacral segments at P7. A delay of two days was observed between the arrival of the corticospinal axons at a given spinal cord level and their outgrowth into the adjacent spinal

Correspondence: Th.G.M.F. Gorgels, Department of Anatomy and Embryology, P.O. Box 9101, University of Nijmegen, 6500 HB Nijmegen, The Netherlands. 
gray. Electron microscopic analysis revealed the presence of numerous growth cones in the growth zone of the developing pyramidal tract [4].

Recently, the presynaptic neuron-specific phosphoprotein B-50 $[5,6,29]$ is shown to be a member of the class of growth-associated proteins (GAPs) [23, 24], presumably identical to GAP43 [9, 28], GAP48 [19], F1 [7] and pp46 [14, 20]. This protein is a prominent substrate to protein kinase $\mathrm{C}$ in growth cones membranes and outgrowing neurites in fetal and postnatal rat brain $[2,15,18]$ and in outgrowing processes of differentiated PC12 cells [26]. By means of radioimmunoassay for B-50 [16], the highest levels of B-50 are determined in developing nervous systems and in regenerating axons following lesion of peripheral nerve $[27,28]$. From these studies, it is apparent that the B-50 (GAP43) protein can be used as a selective marker of neurite outgrowth in developing neural tissue. Indeed, Kalil and Skene [10] have shown that the biosynthesis of GAP43 (B-50) is enhanced during development of the pyramidal tract neurons in hamsters and declines at the time when the axons stop elongating. In the present study using affinity-purified anti-B-50 immunoglobulins (IgGs) [17], we document changes in B-50 distribution in the developing pyramidal tract of the rat reflecting different stages of maturation.

Wistar rats aged 2 days, 7 days and 90 days were anaesthetized by injections with Nembutal and perfused intracardially with a fixative consisting of $2 \%$ paraformaldehyde, $0.5 \%$ glutaraldehyde, and $0.1 \%$ dimethylsulfoxide in $0.1 \mathrm{M}$ phosphate buffer, pH 7.4 [6]. After perfusion the cervical spinal cord was removed and immersed for $2 \mathrm{~h}$ in the fixative. Subsequently, the third cervical segment was dissected out, rinsed in buffer, dehydrated and embedded in Epon. Transverse sections of $1 \mu \mathrm{m}$ were cut and mounted on glass slides coated with chrome-alum gelatine. Epon was removed from the tissue according to Lane and Europa [11]. Endogenous peroxidase activity was blocked with $0.3 \%$ hydrogenperoxide in methanol for $20 \mathrm{~min}$. After hydration the sections were stained for B-50 using the peroxidase-antiperoxidase (PAP) technique [25]. This involved an incubation of the sections in $0.03 \%$ normal goat serum in $0.05 \mathrm{M}$ Tris- $\mathrm{HCl}$ buffer containing $0.9 \% \mathrm{NaCl}, \mathrm{pH} 7.6$ (TBS), followed by an overnight incubation at $4^{\circ} \mathrm{C}$ in affinity-purified rabbit anti-B-50 IgGs [15, 17] diluted 1:500 in TBS. After rinsing in TBS, the sections were treated for 30 min with goat anti-rabbit IgG (Nordic), diluted 1:30 in TBS. The sections were rinsed in TBS and incubated for $1 \mathrm{~h}$ in PAP complex (Dakopatts) diluted 1:90 in TBS. After rinsing in TBS, the sections were incubated for $15 \mathrm{~min}$ in $0.05 \%$ diaminobenzidine tetra-

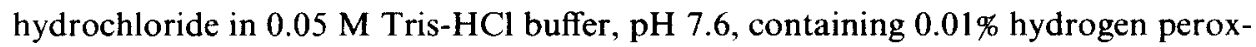
ide. The staining reaction was terminated in distilled water. Subsequently, the sections were dehydrated and embedded in Entellan. The controls with the pre-immune serum and without primary antibodies were negative. Two animals per age group were examined, giving similar results. To determine the B-50 content of spinal cord sections, B-50 was assayed by means of a radio-immunoassay (RIA) as reported by Oestreicher et al. [16]. Wistar rats at P7 and P90 were sacrificed by decapitation. The cervical segment 3 (approx. $3 \mathrm{~mm}$ thick) was dissected from the spinal cord and homogenized as described previously. Protein content was determined by the procedure of Lowry et al. [12]: $n=3$, g protein/g wet weight tissue, mean \pm S.D.: at P7, $60 \pm 2$ and at $\mathrm{P} 90,94 \pm 10$. 
During postnatal development of the rat CNS, at P2 and P7, B-50 immunoreactivity (BIR) is found in the gray as well as in the white matter of the third cervical segment (Fig. 1, panel 1 and 3). In the young adult rat at P90, BIR is considerably reduced in the spinal cord (Fig. 1, panel 5). In this study we focus on the outgrowth of the pyramidal tract in comparison to the two other fiber tracts in the funiculus posterior, which are differentially stained. At $\mathbf{P} 2$ the pyramidal tract shows the most intense immunoreaction, whereas the long ascending fiber tracts, the fasciculus gracilis and notably the fasciculus cuneatus are less intensely stained (Fig. 1, panel

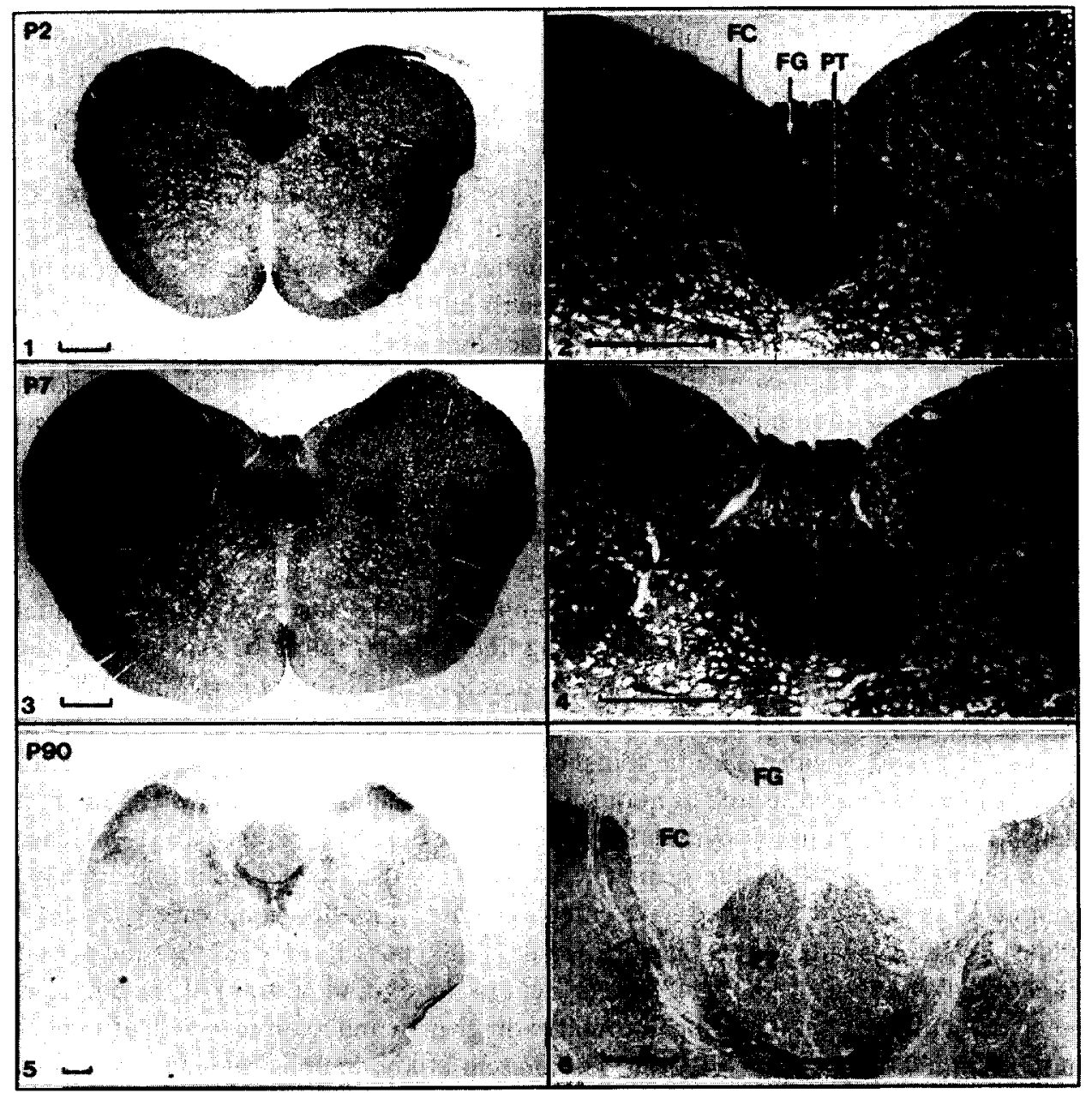

Fig. 1. Distribution of B-50 immunoreactivity (BIR) in transverse sections of the spinal cord at the third cervical segment in the 2-day-old rat (P2: panel 1 and 2), the 7-day-old rat (P7: panel 3 and 4) and the 3-month-old rat (P90: panel 5 and 6). High BIR was detected in the pyramidal tract (PT) at P2 and P7, while at $P 90$ still a reduced BIR is observed. The fasciculus gracilis (FG) and the fasciculus cuneatus (FC) show at P2 less BIR than the pyramidal tract. Moreover, the immunoreaction in the FG and FC is reduced at $\mathrm{P} 7$ and virtually absent at $\mathrm{P} 90$. $\mathrm{Bar}=200 \mu \mathrm{m}$. 
1 and 2). The posterior median septum is not stained. The unstained profiles in the pyramidal tract probably represent glial cells and blood vessels. At P7 BIR is differentially distributed in the gray and white matter (Fig. 1, panel 3). In the dorsal funiculus the densely stained pyramidal tract stands out against the adjacent ascending fiber tracts, in which BIR is strongly reduced as compared to P2 (Fig. 1, panel 3 and 4). By 3 months of age (P90) BIR has decreased and is sparsely distributed in discrete areas of the gray and white matter (Fig. 1, panel 5). The area of the pyramidal tract in the dorsal funiculus displays clear, although reduced, reaction to the B-50 antibodies in tiny dots. The fasciculi gracilis and cuneatus however, are devoid of BIR (Fig. 1, panel 6).

Independently, the amount of B-50 present in the cervical segment $\mathrm{C}_{3}$ of the spinal cord at P7 and P90 was determined by means of a RIA according to Oestreicher et al. [16]. A 10-fold decrease in B-50 content at P90, as compared to P7, was found ( $n=3: \mathrm{P} 7500 \pm 60$ vs $\mathrm{P} 90,50 \pm 6 \mathrm{ng} \mathrm{B}-50 / \mathrm{mg}$ protein).

Using affinity-purified anti-B-50 IgGs [17] we described changes in the pattern of $B I R$ in the cervical segment $C_{3}$ of the spinal cord of the rat related to the developmental stage. The work of Gribnau et al. [8] indicates that elongation of corticospinal axons in the white matter and their outgrowth into the gray matter are still in progress at P2 as well as at P7. It is at these stages that we found most BIR in the developing pyramidal tract axons. In the full grown pyramidal tract of the young adult rat, however, the immunoreactivity in the axons passing the cervical segment $C_{3}$ was considerably reduced.

In the ascending fiber systems of the dorsal funiculus, i.e. the fasciculi gracilis and cuneatus, of the neonatal rat, BIR was less intense than in the axons of the pyramidal tract. Moreover, BIR in the ascending tracts decreased considerably from P2 to P7, whereas in the young adult no immunostaining could be observed. The differential BIR of the pyramidal tract vs the ascending fiber systems might be explained by the fact that the fasciculi gracilis and cuneatus develop earlier than the pyramidal tract. According to Altman and Bayer [1] these tracts develop several days before birth in the upper cervical segments of the spinal cord. Myelination starts at the time of birth in the fasciculus cuneatus and at about P4 in the fasciculus gracilis, whereas the first signs of myelination in the pyramidal tract are not observed before P10 [13]. Hence it can be deduced that in the neonatal rat large numbers of ascending fibers have completed their outgrowth and have entered a stage of maturation, while pyramidal axons are still growing to their targets. Kalil and Skene [10] reported that the period of elevated synthesis of a GAP43-like protein in the pyramidal tract of the hamster, coincides with the period in which normal axon growth and axon regrowth after neonatal pyramidal tract injury occurs. The present study demonstrates high levels of B-50 by immunocytochemical localization and RIA that coincide with axon growth. This gives further support to the hypothesis that B-50 plays a role in axon growth $[3,28]$.

The significance of the persistence of a low amount of B-50 in the pyramidal tract of the young adult rat remains to be established. In line with the proposed function of $\mathrm{B}-50$ in the adult $[3,5,22]$ and in the developing nervous system, one might specu- 
late that the B-50 present in the pyramidal tract of the young adult rat reflects a capacity for remodeling in this system at this age. The differential staining of the tracts in the dorsal funiculus indicate that the neuron-specific B-50 probe is a useful marker for the study of differentially outgrowing fiber tracts.

\section{We would like to thank Harrie T.H. van Aanholt and Ruud J. Bloemen for their expert technical assistance and Margreet A. Rieck for her secretarial assistance.}

1 Altman, J. and Bayer, S.A., The development of the rat spinal cord. In F. Beek, W. Hild, J. van Limborgh, R. Ortmann, J.E. Pauly and T.H. Schiebler (Eds.), Advances in Anatomy, Embryology and Cell Biology, Vol. 85, Springer, Berlin, 1984, pp. 1-166.

2 De Graan, P.N.E., Van Hooff, C.O.M., Tilly, B.C., Oestreicher, A.B., Schotman, P. and Gispen, W.H., Phosphoprotein B-50 in nerve growth cones from fetal rat brain, Neurosci. Lett., 61 (1985) 235241.

3 De Graan, P.N.E., Oestreicher, A.B., Schrama, L.H. and Gispen, W.H., Phosphoprotein B-50: localization and function. In W.H. Gispen and A. Routtenberg (Eds.), Phosphoproteins in Neuronal Function, Progress in Brain Research, Vol. 69, Elsevier, Amsterdam, 1986, pp. 37-50.

4 De Kort, E.J.M., Gribnau, A.A.M., Van Aanholt, H.T.H. and Nieuwenhuys, R., On the development of the pyramidal tract in the rat. I. The morphology of the growth zone, Anat. Embryol., 172 (1985) 195-204.

5 Gispen, W.H., Phosphoprotein B-50 and polyphosphoinositides in the brain synaptic plasma membranes: a possible feedback relationship, Trans. Biochem. Soc. Trans. U.K., 14 (1986) 163-165.

6 Gispen, W.H., Leunissen, J.L.M., Oestreicher, A.B., Verkleij, A.J. and Zwiers, H., Presynaptic localization of B-50 phosphoprotein: the ACTH-sensitive protein kinase substrate involved in rat brain phosphoinositide metabolism, Brain Res., 328 (1985) 381-385.

7 Gispen, W.H., De Graan, P.N.E., Chan, S.Y. and Routtenberg, A., Comparison between the neural acidic proteins B-50 and F1. In W.H. Gispen and A. Routtenberg (Eds.), Phosphoproteins in Neuronal Function, Progress in Brain Research, Vol. 69, Elsevier, Amsterdam, 1986, pp. 383-386.

8 Gribnau, A.A.M., De Kort, E.J.M., Dederen, P.J.W.C. and Nieuwenhuys, R., On the development of the pyramidal tract in the rat. II. An anterograde tracer study of the outgrowth of the corticospinal fibers, Anat. Embryol., 175 (1986) 101-110.

9 Jacobson, R.D., Virag, I. and Skene, J.H.P., A protein associated with axon growth, GAP43, is widely distributed and developmentally regulated in rat CNS, J. Neurosci., 6 (1986) 1843-1855.

$10 \mathrm{Kalil,}$ K. and Skene, J.H.P., Elevated synthesis of an axonally transported protein correlates with axon outgrowth in normal and injured pyramidal tracts, J. Neurosci., 6 (1986) 2563-2570.

11 Lane, B.P. and Europa, D.L., Differential staining of ultrathin sections of Epon-embedded tissues for light microscopy, J. Histochem. Cytochem., 13 (1965) 579-582.

12 Lowry, O.H., Rosebrough, N.J., Farr, A.L. and Randall, R.J., Protein measurement with the Folin phenol reagent, J. Biol. Chem., 193 (1951) 265-275.

13 Matthews, M.A. and Duncan, D., A quantitative study of morphological changes accompanying the initiation and progress of myelin production in the dorsal funiculus of the rat spinal cord, J. Comp. Neurol., 142 (1971) 1-22.

14 Meiri, K.F., Pfenninger, K.H. and Willard, M.B., Growth-associated protein, GAP43, a polypeptide that is induced when neurons extend axons, is a component of growth cones and corresponds to pp46, a major polypeptide of a subcellular fraction enriched in growth cones, Proc. Natl. Acad. Sci. USA, 83 (1986) 3537-3541.

15 Oestreicher, A.B. and Gispen, W.H., Comparison of the immunocytochemical distribution of the phosphoprotein B-50 in the cerebellum and hippocampus of immature and adult rat brain, Brain Res. 375 (1986) 267-279.

16 Oestreicher, A.B., Dekker, L.V. and Gispen, W.H., A radioimmunoassay for the phosphoprotein B-50 distribution in rat brain, J. Neurochem., 45 (1986) 1366-1369. 
17 Oestreicher, A.B., Van Dongen, C.J., Zwiers, H. and Gispen, W.H., Affinity purified anti-B-50 protein antibody: interference with the function of the protein B-50 in synaptic plasma membranes, J. Neurochem., 41 (1983) 331-340.

18 Oestreicher, A.B., Zwiers, H., Gispen, W.H. and Roberts, S., Characterization of infant rat cerebral cortical membrane proteins phosphorylated in vivo: identification of ACTH-sensitive phosphoprotein B-50, J. Neurochem., 39 (1982) 683-692.

19 Perrone-Bizzozero, N.I., Finklestein, S.P. and Benowitz, L., Synthesis of a growth-associated protein by embryonic rat cerebrocortical neurons in vitro, J. Neurochem., 6 (1986) 3721-3730.

20 Pfenninger, K.F., Of nerve growth cones, leukocytes and memory: second messenger systems and growth-regulated proteins, Trends Neurosci., 9 (1986) 562-565.

21 Schreyer, D.J. and Jones, E.G., Growth and target finding by axons of the corticospinal tract in prenatal and postnatal rats, Neuroscience, 7 (1982) 1837-1853.

22 Routtenberg, A., Synaptic plasticity and protein kinase C. In W.H. Gispen and A. Routtenberg (Eds.), Phosphoproteins in Neuronal Function, Progress in Brain Research, Vol. 69, Elsevier, Amsterdam, 1986, pp. 2I1-234.

23 Skene, J.H.P. and Willard, M., Changes in axonally transported proteins during axon regeneration in toad retinal ganglion cells, J. Cell Biol., 89 (1981) 86-95.

24 Skene, J.H.P. and Willard, M., Axonally transport proteins associated with axon growth in rabbit central and peripheral nervous systems, J. Cell Biol., 89 (1981) 96-103.

25 Sternberger, L., Immunocytochemistry, 2nd edn., Wiley, New York, 1979.

26 Van Hooff, C.O.M., De Graan, P.N.E., Boonstra, J., Oestreicher, A.B., Schmidt-Michels, M.H. and Gispen, W.H., Nerve growth factor enhances the level of the protein kinase $C$ substrate B-50 in pheochromocytoma PC12 cells, Biochem. Biophys. Res. Comm., 139 (1986) 644-651.

27 Verhaagen, J., Van Hooff, C.O.M., Edwards, P.M., De Graan, P.N.E., Oestreicher, A.B., Schotman, P., Jennekens, F.G.I. and Gispen, W.H., The kinase C substrate protein B-50 and axonal regeneration, Brain Res. Bull., 17 (1986) 737-741.

28 Zwiers, H., Oestreicher, A.B., Bisby, M.A., De Graan, P.N.E. and Gispen, W.H., Protein kinase C substrate B-50 in adult and developing rat brain is identical to axonally-transported GAP43 in regenerating peripheral rat nerve. In R.S. Smith and M.A. Bisby (Eds.), Axonal Transport, Neurology and Neurobiology, Vol. 25, Liss, New York, 1987, pp. 421433.

29 Zwiers, H., Schotman, P. and Gispen, W.H., Purification and some characteristics of an ACTH-sensitive protein kinase and its substrate protein in rat brain, J. Neurochem., 34 (1980) 1689-1699. 